\title{
Corrección transobturatoria de los cistoceles
}

\author{
P. Palma, A. Rane*, C. Riccetto, V. Herrmann, M. Dambros, A. Tarazona \\ Servicio de Uroginecología, Universidade Estadual de Campinas-UNICAMP, Campinas, Brasil \\ *Profesor de Ginecología y Consultor en Uroginecología, James Cook School of Medicine, Townsville, Australia
}

Actas Urol Esp 2005; 29 (1): 89-92

\begin{abstract}
RESUMEN
CORRECCIÓN TRANSOBTURATORIA DE LOS CISTOCELES

Objetivo: Presentar nuestra experiencia inicial con el sistema Perigee para la corrección de prolapsos de pared anterior vaginal.

Material y método: 15 pacientes con prolapso de la pared anterior de la vagina (edad media: 62 años) fueron intervenidas con el sistema Perigee compuesto de una tela para la corrección del defecto central y cuatro astas autofijables para la corrección del defecto lateral. La técnica de implante consta de cuatro pasos: 1) disección lateral vaginal hasta rama isquiopúbica; 2) realización de dos marcas superiores en el pliegue genito-femoral y dos inferiores a $2 \mathrm{~cm}$ lateralmente y $3 \mathrm{~cm}$ inferiormente en relación a las primeras; 3) introducción agujas superiores paralelas a la rama isquiopúbica y conexión con los "brazos" del injerto e introducción de agujas inferiores verticalmente con conexión a las "piernas" del injerto; 4) ajuste sin tensión de la malla. La tasa de curación fue medida objetivamente utilizando el sistema POP-Q.

Resultados: El punto Aa preoperatorio paso de 0.09 a -3.00 a las 6 semanas del postoperatorio y se mantuvo en -2.73 a los tres meses. El punto Ba preoperatorio era de 1.73 y paso a -2.82 a las 6 semanas y se mantuvo en -2.82 a los 3 meses.

Las complicaciones no fueron significativas. No se produjeron daños vasculares ni sangrados significativos.

Conclusiones: La corrección transobturadora de los cistoceles es una opción atrayente. Los buenos resultados iniciales prometen ser duraderos.
\end{abstract}

Palabras Clave: Cistocele, corrección transopturotriz.

\section{ABSTRACT}

TRANSOBTURATOR CORRECTION OF CYSTOCELE

Objective: We present our initial experience with the Perigee system for anterior vaginal wall prolepses repair.

Material and method: 15 patients with anterior vaginal wall prolapse (mean age: 62 years old) underwent implanted with Perigee system which is composed by a mesh for correcting central defect and four self-attached horns for correcting lateral defect. The implanted procedure consist of four steps: 1) lateral vaginal wall dissection as far as isquiopubic branch; 2) performance of two upper marks at genitofemoral foldy and two lower marks at $2 \mathrm{~cm}$ laterally and $3 \mathrm{~cm}$ lower; 3) insertion of the upper needles parallel to the isquiopubic branch and connection with the mesh's "arms" plus insertion of the lower needles vertically and connection with mesh's "legs"; 4) to adjust the mesh free tension. The system POP-Q was used as an objective measure of correction rate.

Results: Preoperatively, the point Aa was 0.09. After 6 weeks and three months postoperatively was -3.00 and -2.73 respectively. Preoperatively, the point Ba was 1.73. After 6 weeks and three months postoperatively was -2.82 and -2.82 respectively. No major complications were presented. No vascular damage or significant bleeding was observed.

Conclusion: The transobturator correction of cystocele is and attractive alternative. The initial good outcome may be expected to be long lasting.

Key Words: Cystocele, trasnsopturator correction.

$\mathrm{E}$ 1 prolapso de la pared anterior de la vagina es muy frecuente, alcanzando el $11 \%$ en las mujeres americanas. El riesgo de desarrollar cistocele, se duplica en cada década de la vida y se estima que 2.9 millones de mujeres presentarán cistoceles grado III y IV en los Estados Unidos de América del Norte ${ }^{1}$.

El concepto de biocirugía, término acuñado por Hubert Manhes, en Francia ${ }^{2}$, tuvo gran im- portancia en el avance de la cirugía mínimamente invasiva laparoscópica y también en el desarrollo de los procedimientos transobturato$\operatorname{rios}^{3-5}$. Manhes, defiende la idea de que los cirujanos de este siglo, deben dejar de lado la concepción netamente mecánica de las cirugías, ya que trabajan en tejidos vivos, que tienen sus propias leyes de cicatrización y reparo. La biocirugía valoriza los principios de la cirugía clásica, aso- 
ciado al refuerzo de los tejidos, inducido por biomateriales, caracterizada por los siguientes principios:

1. Abordaje mínimamente invasivo.

2. Investigación de planos anatómicos y fisiológicos.

3. Mínimo trauma.

4. Respeto de la ingeniería de tejidos y sus ecosistemas específicos.

5. Aportar soluciones propias, que estimulan y canalizan reacciones en el organismo, donde son necesarias.

6. Ausencia de fijación (la sutura causa necrosis e infección).

7. Resultados anatómicos y funcionales inmediatos.

El sistema transobturatorio para la corrección de los prolapsos de la pared anterior de la vagina "Perigee" ejemplifica esta tendencia de las nuevas técnicas quirúrgicas. Este sistema esta compuesto de una tela para la corrección del defecto central y cuatro astas autofijables para la corrección del defecto lateral (Fig. 1), por vía transobturadora.

$\mathrm{El}$ objetivo de este trabajo es presentar nuestra experiencia inicial con este nuevo sistema de corrección de prolapsos de la pared anterior vaginal,

\section{PACIENTES Y MÉTODO}

Muestra.- La muestra consta de un total de 15 pacientes con prolapso de la pared anterior de la vagina. La edad media de las pacientes fue de 62 años (rango 38-78). La paridad media de 3,8 y el

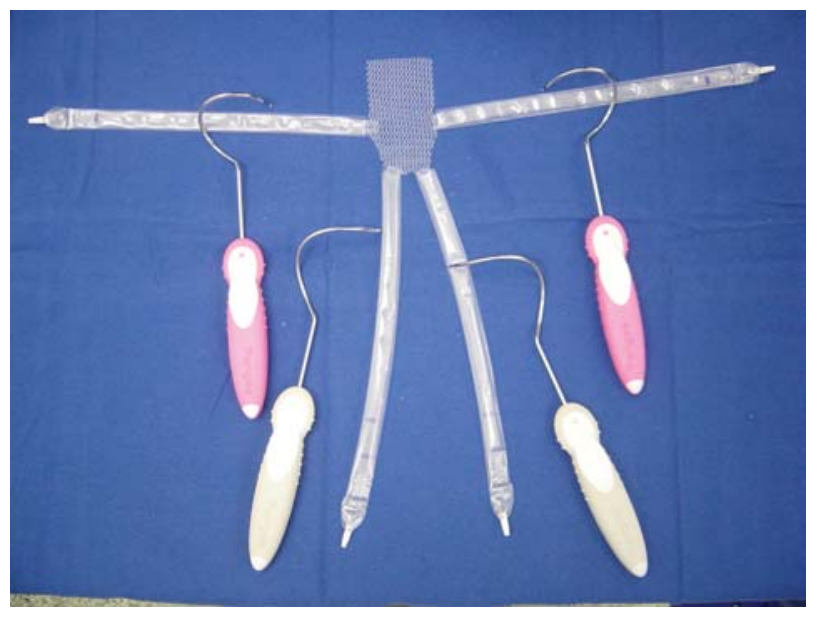

Figura 1. peso medio de $72 \mathrm{Kg}$. Nueve de las pacientes $(60 \%)$ habían sido histerectomizadas previamente y $7(46 \%)$ ya habían sido intervenidas mediante una plastia anterior como primer intento de curación. En cuanto al tipo de defecto a nivel de la pared anterior, 8 presentaban un defecto lateral, 2 central y 2 padecían ambos. En una de las pacientes no se logró determinar.

Técnica quirúrgica.- La técnica quirúrgica de implantación del sistema consta de cuatro pasos:

Primer paso: Con el paciente en posición de litotomía, se colocan dos pinzas de Allis a nivel del cuello vesical. Se infiltra la pared vaginal con solución de Lidocaína al 1\% con Adrenalina para facilitar la disección y la hemostasia. Se realiza una incisión mediana en la pared anterior de la vagina entre las pinzas de Allis previamente colocadas. La disección lateral debe ser realizada hasta la rama isquio-púbica, lo suficiente como para permitir el paso de las cuatro agujas del conjunto de Perigge. Inferiormente la base del cistocele se debe disecar hasta la cúpula vaginal. Generalmente la disección superior no es necesaria (Fig. 2).

Segundo paso: En seguida, se realizan las marcas en los sitios de introducción de las agujas. Las superiores, de manera similar al Monarc, son hechas en el pliegue genito-femoral a nivel del clítoris. Las inferiores, se realizan a $2 \mathrm{~cm}$ lateralmente y $3 \mathrm{~cm}$ inferiormente en relación a las primeras (Fig. 3).

Tercer paso: Las agujas superiores son introducidas paralelamente a la rama isquio-púbica, y

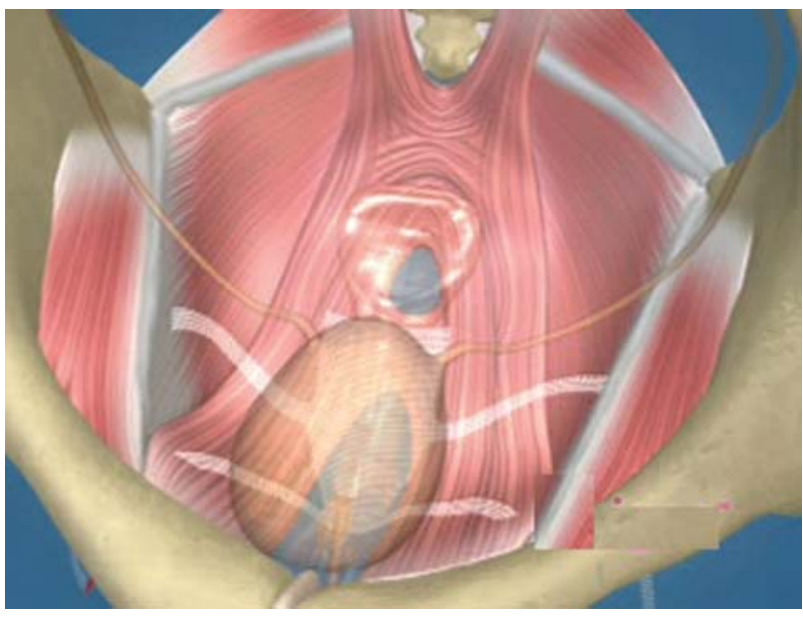

Figura 2. 
exteriorizadas por la incisión vaginal, simplemente por la rotación de los puños, guiadas por el dedo índice del cirujano. Los "brazos" del injerto son conectados a las extremidades de las agujas por los respectivos dilatadores y traídos hacia la región vulvar. Una vez realizado lo anterior, se procede a la introducción de las agujas inferiores. A diferencia de las superiores, estas agujas son introducidas verticalmente, para facilitar el paso rodeando el segmento más grueso del hueso. Nuevamente los dilatadores son encajados en las extremidades de las agujas y las "piernas" del injerto traídas a la región vulvar (Fig. 4).

Cuarto paso: La tela debe generar un soporte sin tensión para el cistocele. El excedente inferior se reseca y las fundas plásticas son removidas de los brazos y piernas de los injertos. Si son necesarios, se pueden realizar pequeños ajustes en este momento. Las partes excedentes de los brazos y las piernas son removidas y las incisiones se cierran de manera convencional. La utilización del catéter de Foley y tampón vaginal en el postoperatorio inmediato son imperativos. Se recomienda terapia antimicrobiana profiláctica y analgésica, de acuerdo con el protocolo de la institución. La paciente debe abstenerse de la actividad sexual y los ejercicios físicos por cuatro semanas.

Evaluación resultados.- La tasa de curación fue medida objetivamente utilizando el sistema

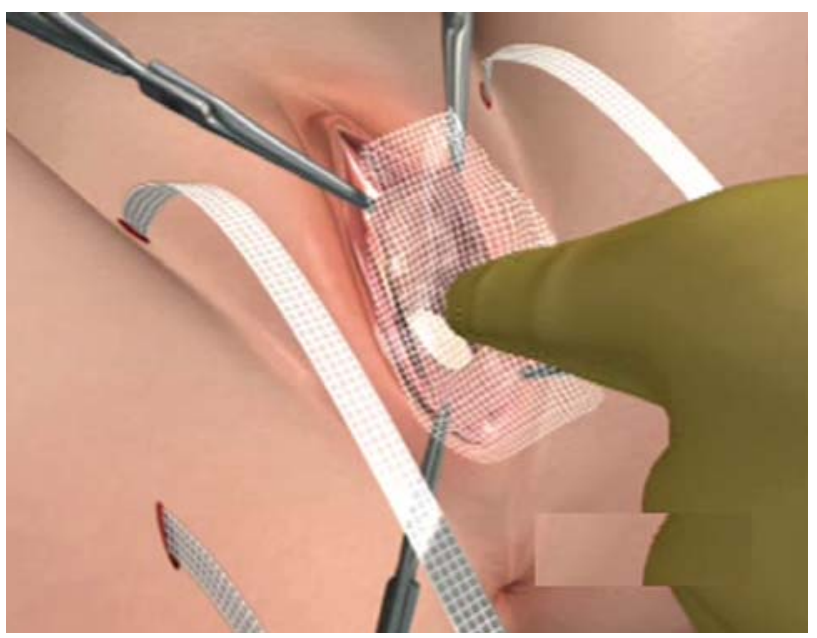

Figura 3, Las incisiones superiores son realizadas en el pliegue genitofemoral $y$ las inferiores son realizadas 2 cm lateralmente y 3 inferiormente a las primeras.

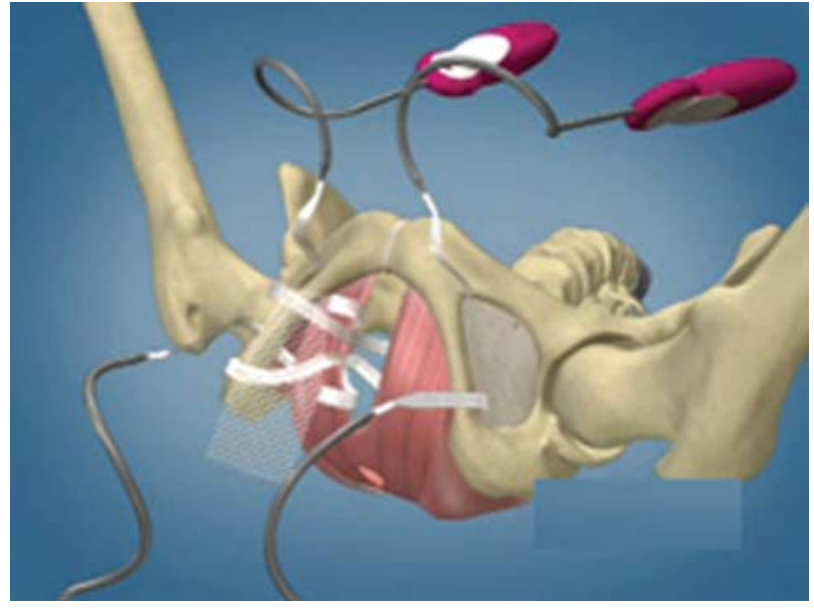

Figura 4. A diferencia de las superiores, las agujas inferiores son introducidas verticalmente, para facilitar el contorno de la parte más gruesa del isquium.

de gradación POP-Q. De esta forma, se pudo evaluar la diferencia en cuanto al soporte anterior de la vagina.

\section{RESULTADOS}

Los resultados comparando los hallazgos de la exploración clínica preoperatoria con los de a las 6 semanas y los tres meses se exponen en la Tabla 1. Las complicaciones no fueron significativas. No se produjeron daños vasculares ni sangrados significativos. En un paciente, se produjo una pequeña perforación vesical durante la disección de la pared vaginal. Mediante sutura simple y catéter uretral se solventó el problema. Una de las pacientes presentó infección urinaria que fue tratada con antimicrobianos adecuados. En dos casos se utilizaron estrógenos tópicos para el tratamiento de dos pequeñas protrusiones.

\section{DISCUSIÓN}

Este procedimiento representa un gran avance en la cirugía pélvica reconstructiva, una vez que la recurrencia de los cistoceles es del 30\%

Tabla 1

POP-Q evaluación pre y post operativa

\begin{tabular}{lccc}
\hline & Pre-op & 6 semanas & 3 meses \\
\hline $\mathrm{Aa}$ & 0.09 & -3.00 & -2.73 \\
$\mathrm{Ba}$ & 1.73 & -2.82 & -2.82 \\
\hline
\end{tabular}


en el primer año. Por otro lado la utilización de telas biocompatibles representa un índice de cura muy superior, que alcanza el 94\%. Además de la seguridad, el carácter mínimamente invasivo de esta técnica, reduce significativamente las complicaciones de los procedimientos tradicionales, tales como la dispareunia y la estenosis del canal que ocurre en el 19 al $32 \%$ de los casos.

Un detalle técnico importante, es la mínima resección de la pared vaginal, una vez que ella no es la causa, mas si la consecuencia del prolapso y por ende su preservación garantiza la corrección sin tensión, condición fundamental para el éxito del procedimiento.

La nueva tela "Intepro" constituye otro punto importante de este concepto. Una vez que los nuevos biomateriales son puntos relevantes de la biocirugia. Esta tela posee características de maleabilidad, que evita isquemia de los tejidos y macroporos que permiten a los macrófagos fagocitar bacterias que eventualmente pudieran contaminar la prótesis, contribuyendo sobremanera al éxito de la cirugía.

Es importante aclarar que las astas de fijación corrigen el defecto lateral y la tela con macroporos, corrige el defecto central. Así de manera análoga a la corrección contemporánea de las hernias inguinales, este procedimiento democratiza los resultados favorables, en función de la padronización y reproducibilidad.

En cuanto a las posibles lesiones vasculares, los buenos resultados obtenidos con el tratamiento transobturatorio de la incontinencia urinaria de esfuerzo ${ }^{3-5}$ y estudios anatómicos ${ }^{6}$, comprueban, que este abordaje es seguro y no han sido descritas lesiones vasculares significativas.

La tasa de curación fue muy Buena y fue medida objetivamente utilizando el sistema de gradación POP-Q. De esta forma, se pudo comprobar como el sistema obtuvo un buen soporte anterior de la vagina. Aunque hasta el momento no se hemos tenido complicaciones ni efectos secundarios relacionados con la utilización de la malla con este seguimiento corto, son necesarios estudios posteriores y con mayor evolución para evaluar su repercusión sobre la función sexual y funcional.

La corrección transobturadora de los cistoceles es una opción atrayente, especialmente para casos complejos y reoperaciones, pudiendo tener indicación rutinaria, ya que los buenos resultados iniciales prometen ser duraderos.

\section{REFERENCIAS}

1. Moore R. Incidence and prevalence of pelvic organ prolapse. In New Techniques in Pelvic Floor Recontruction. Minneapolis Mn, 2004. American Medical Systems.

2. Manhes H. Laparoscopic Retzio-plasty. A new surgical approach to stress incontinence. Int Surg.1996; OctDec;81(4):371-373.

3. Delorme E, Droupy S, de Tayrac R, Delmas V. Transobturator tape (Uratape). A new minimally-invasive procedure to treat female urinary incontinence. Eur Urol. 2004;Feb; 45(2):203-207.

4. Palma PCR, Fraga R. Sling Transobturatório Reajustável: Uma abordagem promissora na Incontinência Urinária de esforço. Urologia Contemporânea 2002:4: 146-148.

5. Palma PCR, Riccetto CLZ, Fragra R, Dambros M, Thiel M, Borges GM, Netto NR Jr.: "Sling" transobturatório: uma nova opção mínimamente invasiva para otratamento da incontinência urinária de esforço. Urodinâmica \& Uroginecologia 2002;5(3)109-113.

6 Walters MD, TulikangaPK, LaSala C, Muir TV: Vascular injury during tension-free vaginal tape procedure for stress urinary incontinence. Obstet Gynecol 2001;98:957-959.

Dr. Paulo C.R. Palma

Rua Jose Pugliese Filho 265

Chacara Sanat Margarida

Campinas, SP BRASIL -

13085-032

(Trabajo recibido el 13 diciembre de 2004) 